\title{
Michel Foucault, Historia de la sexualidad 4: las confesiones de la carne, Buenos Aires, Siglo XXI, 2019, 458 pp.
}

$\mathrm{E}^{\mathrm{n}}$ n la contratapa de la primera edición del primer tomo de la Historia de la sexualidad titulado La voluntad de saber (1976) se presentaba un plan futuro de publicaciones que continuaría con la investigación iniciada por Michel Foucault en cinco libros cuyos títulos eran los siguientes: La carne y el cuerpo, La cruzada infantil, La mujer, la madre y la histérica, Los perversos, Población y razas. Se supone que de los volúmenes segundo al quinto Foucault recorrería los elementos que configuran lo que había denominado en el tomo inicial el "dispositivo de sexualidad", mientras que en el sexto regresaría a la problemática del concepto de biopoder situado en el capítulo quinto también del primer volumen. Desde luego, ninguno de estos libros será publicado tal como estaba anunciado. Sin embargo, a través de los Archivos Foucault (cuarenta mil folios repartidos en un centenar de cajas bajo la signatura NAF 28730) depositados en el Departamento de Manuscritos de la Biblioteca Nacional de Francia, tomamos conocimiento que por lo menos dos títulos (La carne y el cuerpo y La cruzada infantil) ya habían sido parcialmente redactados.

Luego de abandonado este plan de publicaciones tras un lapso de ocho años se publican conjuntamente los volúmenes dos y tres bajos los títulos El uso de los placeres y La inquietud de sí
(1984). Finalmente, en 2018 se edita en Francia el cuarto tomo de la serie titulado Las confesiones de la carne cuya edición al castellano bajo la traducción de Horacio Pons lanza Siglo XXI Editores dentro de la serie Fragmentos Foucaultianos que dirige Edgardo Castro.

La génesis de la investigación y escritura del tomo cuarto es extensa y compleja, y es reconstruida de manera detallada por Frédéric Gros en la Nota preliminar de la edición francesa. En el proyecto originario (dejado de lado) de la Historia de la sexualidad, la problemática de la confesión y de la carne en tanto sustancia ética del cristianismo se situaría en el volumen titulado La carne y el cuerpo. Estas investigaciones habían sido iniciadas por Foucault por lo menos desde 1975 en el curso del Collège de France titulado Los anormales, particularmente en la clase del 19 de febrero, donde el filósofo francés desarrolla la cuestión de la exigencia de verbalización de la verdad por parte del sujeto. Es posible rastrear notas de lecturas de Foucault sobre Tertuliano y Casiano de 1976, y en la cronología que realiza Daniel Defert en Dits et écrits se señala que el autor en agosto de 1977 está en Vendeuvre investigando sobre los $\mathrm{Pa}$ dres de la Iglesia. Este primer acercamiento de Foucault a los textos de la Patrística es el punto de partida de un giro no menor en su programa intelec- 
tual que comienza a perfilar el estudio de las "gubernamentalidades", eje central de los cursos del Collège de France titulados Seguridad, territorio, población (1977-1978) y Nacimiento de la biopolítica (1978-1979) que dan inicio a la analítica del liberalismo y neoliberalismo a partir de la noción de "gobierno por la verdad". Aproximación que se ampliará en 1979-1980 en el curso titulado Del gobierno de los vivos donde leemos las investigaciones de Foucault sobre las obligaciones cristianas del decir verdadero en relación al bautismo, la penitencia y la dirección monástica de los siglos II y III. Asimismo, en octubre de 1979 en la primera de las dos conferencias que Foucault dicta en la Universidad de Stanford (editadas bajo el título Omnes et singulatim) ya aparece la problematización del gobierno pastoral.

Los años ochenta serán el modenciar el incremento de las lecturas que posteriormente llevan a Foucault a la escritura del manuscrito de lo que hoy es Las confesiones de la carne. En 1980 Foucault dicta en la Universidad de California en Berkeley y en el Dartmouth College dos conferencias en las que vuelve sobre estos temas; asimismo, en el marco de un seminario con Richard Sennett en Nueva York presenta un bosquejo de lo que sería Las confesiones de la carne, en particular una indagación muy detallada en torno al concepto de "libido" en San Agustín. Subsiguientemente, es posible afirmar que el tomo cuarto, si bien se estima que fue redactado entre 1981 y 1982 , comienza a ser trabajado por lo menos desde 1975-1976 a partir de las notas preparatorias de las lecturas. Por lo tanto, estamos en presencia de un libro sustancial en el corpus foucaultia-

no que implica un largo aliento en su constitución.

Como advierte Frédéric Gros, la entrega del manuscrito por parte de Foucault y la copia dactilografiada en Gallimard habían sido programadas para el otoño de 1982 pero el filósofo pide no publicar inmediatamente este texto ya que, aconsejado por Paul Veyne, comienza a trabajar sobre un libro dedicado a la experiencia grecolatina de los aphrodisia que debería anteceder a Las confesiones de la carne. Este libro finalmente será dividido en lo que hoy conocemos como el tomo segundo y el tercero de la serie. Por lo tanto, el trabajo sobre estos dos volúmenes previos retardó la revisión por parte de Foucault de Las confesiones de la carne. Entre marzo y mayo de 1984 el filósofo retoma la corrección de pruebas del tomo cuarto enfermo de gravedad. Al morir el 25 de junio no logra entregar la corrección definitiva. La edición que llega a nuestras manos fue elaborada a partir del manuscrito de Foucault y de la versión tipeada a máquina de Gallimard enviada al filósofo para su revisión final. Es importante destacar, como lo hace Gros, los aportes de Michel Senellart y Philippe Chevallier (que han trabajado en detalle el vínculo de Foucault con el cristianismo) para lograr la recomposición del texto y el chequeo de las citaciones de los autores de los cuales se sirve Foucault. A su vez, se han adicionado cuatro apéndices al final del libro, de los cuales los primeros tres corresponden a folios incluidos en carpetas separadas y dispuestas en el manuscrito de Foucault al final de la primera parte del texto; el apéndice cuarto corresponde a la última elaboración del manuscrito y la copia dactilografiada. 
En la presentación del texto en castellano Edgardo Castro remarca que ya en La arqueología del saber (1969) Foucault daba cuenta de una bisagra de sus investigaciones cuando se interroga si son posibles otras arqueologías que excedan las formas epistemológicas; allí postula la potencialidad de arqueologías de la sexualidad, la pintura y la política. Esta hipotética arqueología de la sexualidad que señala Castro abre la puerta hacia la problematización moral y la subjetivación que aparecerán más tarde en la obra foucaultiana. Sin embargo, en 1964, cinco años antes, el filósofo francés señala una arqueología orientada hacia la ética en el curso recientemente publicado bajo el título La sexualité dictado en la Universidad de Clermont-Ferrand. Como rastrea Castro, allí Foucault sostiene que en los siglos XVII y XVIII las teorías del contrato mostraban que el hombre era, al mismo tiempo, un ser individual y social. Este lugar de entrecruzamiento entre lo psicológico y lo fisiológico será ocupado desde finales del siglo XIX por el concepto de "sexualidad". En este sentido, en Las confesiones de la carne asistimos al despliegue de esta analítica novedosa del gobierno en relación con el deseo y la verdad. Es decir, la obligación a decir la verdad por parte del sujeto y cómo este encuentra esa verdad en su deseo. Estableciendo un orden cronológico de esta "genealogía del hombre de deseo", Foucault se ocupa del problema de los "aphrodisia" en la cultura griega, helenística y romana en los volúmenes dos y tres, de la noción de "carne" en el cristianismo primitivo en el volumen cuarto y del concepto de "sexualidad" en los siglos XIX y XX en el primer volumen. Aphrodisia, carne y sexualidad serán las nominaciones de tres experiencias disímiles del placer y el deseo en la Antigüedad, el cristianismo y la modernidad, respectivamente. La publicación de Las confesiones de la carne es de una relevancia significativa precisamente porque restaba el desarrollo de la experiencia de la "carne" que opera como nexo entre las otras dos, completando de este modo todo el proyecto foucaultiano.

Finalmente, es importante señalar que en la edición castellana al cuidado de Edgardo Castro se han modificado y ajustado algunos criterios normativos en las citaciones del original francés y se han añadido las referencias bibliográficas en lengua castellana de los autores griegos y latinos citados por Foucault.

LUIS DIEGO FERNÁNDEZ UTDT 